\section{A INTERDISCIPLINARIDADE EM \\ PROGRAMA MULTIDISCIPLINAR NO \\ CAMPUS “LUIZ DE QUEIROZ” - USP}

Siu Mui Tsai*

Othon Silva Abrahão**

Para iniciar uma linha de raciocínio sobre a interdisciplinaridade entre temas que podem se relacionar entre si com o foco ecológico, há de se levar em conta as discussões sobre ambiente e desenvolvimento iniciadas nas décadas de 60 e 70 (ROCHA, 2003). A presença clara do objeto de estudo, o ambiente, conduziu rapidamente os olhares ao grande agente de suas transformações, o homem, e aos efeitos planetários advindos de sua ação. Lançam-se assim as bases para a constituição de um pensamento interdisciplinar, em que as ciências biológicas, exatas e humanas passam a travar um intenso diálogo entre as suas disciplinas, exigindo constante revisão de conceitos e a criação e definição de novas matérias e metodologias capazes de explicar e resolver os problemas que passaram a se apresentar e que pareciam insolúveis sob a ótica disciplinar pura. Mais do que meros diálogos, surge a necessidade de verdadeira integração de áreas de conhecimento para o completo entendimento das questões e intensa troca e apropriação de capacidades entre os diferentes atores para a solução das proposituras. Embora à primeira vista se apresente como uma proposta com elevado grau de complexidade, ao final, pode-se perceber que após o aprofundamento na discussão dos problemas, é muito provável que a multiplicidade de conceitos e soluções, aparentemente divergentes, passem a se constituir em um novo senso comum, mais simples. Otimiza-se, assim, o aproveitamento de recursos para a implantação e a viabilização dos programas de gestão a curto, médio e longo prazos.

A problemática ambiental passou a ganhar as instâncias governamentais internacionais, tendo como marco mundial a criação do Programa Internacional de Educação Ambiental da Organização das Nações Unidas (ONU) em 1975

*Engenheira Agrônoma, professora. associada, coordenadora e presidente do PPGI-EA/USP. Coordenadora do Programa de Pós-Graduação em Ecologia de Agroecossistemas, Escola Superior de Agricultura “Luiz de Queiróz” - ESALQ /USP, Piracicaba-SP.

**Engenheiro Agrônomo, doutorando no Programa de Pós-Graduação - Ciências/USP. e, no Brasil, a realização do I Seminário Nacional sobre Universidade e Meio Ambiente em 1986. Destacam-se aí dois aspectos importantes: o da emergência do assunto - priorizado a partir da percepção da urgência em agir sobre ele - e a designação da Universidade (com a pesquisa e a educação) como meio de aprofundar o conhecimento sobre o tema e levar a discussão às sociedades especializadas e à comunidade.

Muitos foram os eventos e instituições que surgiram a partir destas iniciativas, apresentando o ambiente como enfoque central, acompanhados de crescente inclusão do tema na formulação de políticas públicas e instrumentos legais de direcionamento e regulação.

Alguns temas passaram a ganhar importância dentro da discussão, dentre os quais o da biodiversidade na funcionalidade dos ecossistemas tropicais, fortemente ressaltada pela Agenda 21, documento gerado na Conferência da Nações Unidas para o Ambiente e o Desenvolvimento, preparado no Rio de Janeiro em 1992 (www.un.org/spanish/esa/sustdev/agenda21.htm). O documento estimulou a cooperação científica internacional para um melhor entendimento da importância da biodiversidade e suas funções no ecossistemas. Existe atualmente um conjunto consistente de dados experimentais demonstrando que a maioria dos organismos são funcionalmente redundantes e que as características funcionais das espécies componentes são ao menos tão importantes quanto o número de espécies per se para a manutenção dos processos essenciais. Acredita-se que, pelo menos, um mínimo de espécies é essencial para o funcionamento dos ecossistemas sob condições de equilíbrio e que um grande número de espécies sejam provavelmente essenciais para a manutenção de processos estáveis em ambientes que, como o agrícola, estão sob efeito de alterações.

Para essa discussão, tomemos, como exemplo, o tema Biodiversidade, definida como o número de espécies presentes em um dado ecossistema, que tem sido foco de preocupação geral, especialmente quando se trata de regiões tropicais, pois a sua conservação tem sido relegada em função do interesse de apropriação dos recursos naturais existentes. Atualmente, sabe-se da importância do seu papel na manutenção da biosfera funcional, pois atribui-se que (i) através da caracterização da diversidade é possível entender e manipular o funcionamento dos ecossistemas tropicais e (ii) a capacidade de um ecossistema de superar perturbações sérias depende da diversidade do sistema. Citamos como exemplo, a Mata Atlântica, que originalmente cobria cem milhões de hectares. Hoje, em virtude da densa população e industrialização, restam somente cerca de $7 \%$ dessas florestas. Diversos pontos desse bioma são atualmente apontados como sendo hotspots de biodiversidade, locais onde se concentra uma alta diversidade de espécies associada a uma grande ocorrência de endemismos - parâmetros indicadores de prioridade para a conservação e a 
preservação. Apesar de ainda restarem remanescente de Mata Atlântica, o ritmo de destruição vem se acelerando: muitos desses sistemas foram e vêm sendo destruídos, antes mesmo que se tenha desenvolvido o pleno entendimento dessa enorme diversidade de ecossistemas e da riqueza imensurável de espécies, associada a uma grande complexidade de interações entre organismos. A prioridade, no caso da Mata Atlântica, é, portanto, desenvolver tecnologias para a restauração dos ecossistemas degradados da maior parte (93\%) desse bioma, assim como para a preservação dos fragmentos pouco perturbados (7\%) ainda restantes (ver sites www.ibama.gov.br/ecossistemas/mata_atlantica.htm e www.sosmataatlantica.org.br).

O Programa de Pós-Graduação Interunidades em Ecologia de Agroecossistemas - PPGI-EA, iniciado em 2001, consolidou após diversos seminários com a participação de especialistas convidados, docentes e discentes, quatro sub-áreas de concentração: ecologia de agroecossistemas, modelagem ambiental, biologia da conservação, ambiente e sociedade. Este programa tem evoluído com a constante introdução de uma abordagem participativa dos docentes e alunos com comunidades que podem atuar na conservação de fragmentos florestais, já delineados por projetos desenvolvidos segundo princípios da Biologia da Conservação, como por exemplo, as unidades de conservação do Programa Biota da FAPESP, onde atuam diversos docentes e alunos do PPGI-EA. Através do acesso às técnicas atualmente disponíveis nos laboratórios da Escola Superior de Agricultura "Luiz de Queiróz" - ESALQ e do Centro de Energia Nuclear na Agricultura - CENA envolvidos no programa, o aluno complementa a sua capacitação técnica em análise da diversidade e conservação genética de espécies vegetais e da qualidade do solo. O emprego de técnicas avançadas tais como o cultivo de células e uso de marcadores moleculares possibilitam uma maior eficiência em estudos de diversidade genética e caracterização de recursos genéticos e da biodiversidade. A importância dos estudos sobre as interações planta-microrganismos tem sido destaque nos últimos anos, uma vez que essas associações, sob as diversas formas, tais como patogenicidade, simbioses mutalísticas, biocontrole, endofíticas etc. podem causar grande impacto nos ecossistemas perturbados. Esse rápido e crescente aumento no conhecimento pode ser largamente correlacionado com o sucesso da aplicação de métodos bioquímicos e moleculares modernos para elucidação dessas interações em vários ambientes. Através da análise da estrutura das comunidades microbianas pode-se também avaliar as alterações e as perdas da diversidade. Com o advento da era genômica e o acesso à bioinformática, a informação dessa forma disponibilizada pode ser imediatamente transferida para a bancada, permitindo a manipulação segura dos sistemas biológicos de interesse.

Desenvolver uma proposta de ensino, delineada a partir da grade do Programa de Pós-Graduação Interunidades em Ecologia de Agroecossistemas, proposto por docentes da ESALQ e CENA nos níveis de Mestrado e Doutorado, tem possibilitado uma melhoria na integração entre suas linhas de pesquisa. Dessa forma, estabelece-se um melhor entendimento tanto entre docentes como alunos, do papel do homem na aplicação de medidas corretivas para a restauração e conservação de ecossistemas tropicais. O aluno tem a oportunidade de compreender e prever as medidas necessárias para a recuperação de ambientes naturais degradados e do manejo sustentado dos sistemas produtivos, medidos através do uso de técnicas avançadas. Com as medidas das alterações e melhorias na composição da flora, fauna e da biota do solo, ações podem ser previstas para o biomonitoramento e recuperação dos sistemas. A proposta inclui a realização de seminários e uma experiência de ensino, como parte do treinamento dos alunos. Para os mais destacados, são oferecidas oportunidades para acompanhamento direto das disciplinas propostas como estagiários auxiliares. Essas disciplinas essenciais são ministradas nos semestres iniciais, quando o aluno tem a oportunidade de receber os fundamentos básicos para a formação inicial de um profissional capacitado em manejo sustentado de ecossistemas tropicais, que deve apresentar ao final da sua formação, a capacidade de compreensão da problemática e suas possíveis soluções a curto, médio e longo prazos. Ao longo do curso, o aluno recebe treinamento laboratorial para o diagnóstico dos processos alterados e determinação das medidas para o monitoramento qualitativo e quantitativo das alterações. Tem também acesso às técnicas de regeneração dos sistemas biológicos através do entendimento da diversidade de espécies, dinâmica da sucessão, interação planta-animal, planta-microrganismos, além de acesso às técnicas de manipulações genéticas através de cultivos in vitro e resgate de materiais para fins de conservação e biodiversidade, manuseio de técnicas moleculares e de bioinformática, como apoio às pesquisas voltadas à regeneração e melhoria da qualidade e produtividade desses sistemas.

Paralelamente ao desenvolvimento desse processo do PPGI-EA (ESALQ/CENA - USP), que integrou diferentes unidades para seu propósito multidisciplinar, o Centro de Energia Nuclear na Agricultura (CENA-USP), acompanhando as necessidades de desenvolvimento de múltiplas competências e de coordenação em atendimento às áreas de conhecimento da agricultura e ambiente, passou por uma grande reformulação no seu Programa de PósGraduação em Ciências, desdobrando a sua área de concentração original, Energia Nuclear na Agricultura, que vigorou até o início de 2005, em três grandes áreas de concentração - Energia Nuclear, Química e Biologia - mantendo a sua abrangência multidisciplinar, porém, com a possibilidade de interatividade entre as áreas através de eventos científicos delineados pelos docentes e discentes, como as oficinas, seminários e encontros anuais coordenados pelos próprios alunos. 
É necessário, no entanto, que se destaquem os principais desafios enfrentados na construção desse recente conceito de ensino e pesquisa. Estes se encontram, muitas vezes, nas questões cotidianas como, por exemplo, no estabelecimento do espaço comum para o desenvolvimento das atividades, uma vez que a mera apropriação de um projeto por uma disciplina, professor, laboratório ou departamento provoca o desinteresse das áreas complementares, habituadas à independência de atuação presente na Universidade até então. O excesso de burocracia e as disputas internas por espaço e poder podem ser apontados como entraves significativos no processo de construção deste conhecimento interdisciplinar. Associe-se a isso a inexistência ou demora de reconhecimento de determinadas áreas e linhas de pesquisa pelos órgãos de fomento, que acabam provocando o "encaixe" providencial destas em comitês menos afins a analisarem o alcance e/ou mérito das propostas enviadas para avaliação e provimento de recursos.

$\mathrm{O}$ entendimento dessa interdisciplinaridade, com todos seus pontos positivos e negativos a serem destacados, deverá ser o foco principal na estruturação de cursos envolvendo ecologia e ambiente, como instrumento para uma melhor integração de conhecimento e recursos, trazendo antes de tudo, benefícios de ação particularmente local ou regional, sem perder de vista o contexto global.

\section{Referências:}

ROCHA, P.E.D. Trajetórias e perspectivas da interdisciplinaridade ambiental na pós-graduação brasileira. Ambiente \& Sociedade, Campinas, v.6, n.2, p.155-182, 2003.

POMBO, Olga. Interdisciplinaridade e integração dos saberes. Liinc em Revista. Rio de Janeiro, v.1, n.1, p.4-16, 2005.

ALVES, R.F.; BRASILEIRO, M.C.E.; BRITO, S.M.de O.

Interdisciplinaridade: Um conceito em construção. Episteme, Porto Alegre, v.19, p.139-48, 2004. 